\title{
Development of Twenty-Two Novel Cross-Species Microsatellite Markers for Amur sturgeon (Acipenser schrenckii) from Chinese Sturgeon (Acipenser sinensis) via next-Generation Sequencing
}

\author{
Yacheng $\mathrm{Hu}^{1}$, Xueqing $\mathrm{Liu}^{1}$, Jing Yang ${ }^{1}$, Kan Xiao ${ }^{1}$, Binzhong Wang ${ }^{1}$, Hejun $\mathrm{Du}^{1,{ }^{*}}$ \\ ${ }^{1}$ Hubei Key Laboratory of Three Gorges Project for Conservation of Fishes, Institute of Chinese Sturgeon, China Three \\ Gorges Corporation, Yichang, Hubei, 443100, China.
}

\section{Article History}

Received 19 December 2017

Accepted 26 March 2018

First Online 30 March 2018

\section{Corresponding Author}

Tel.: +86.07176713481

E-mail: duhejun21@126.com

\begin{abstract}
In the present study, twenty-two microsatellites was developed for Amur sturgeon (Acipenser schrenckii). All of them were polymorphic with 2 to 7 alleles per locus and the total number of alleles is 106 . The expected heterozygosity $\left(H_{E}\right)$, observed heterozygosity $\left(H_{O}\right)$, polymorphic information content $(P I C)$, Hardy-Weinberg departure value $(d)$ and Shannon-Weiner Diversity Indices $\left(H^{\prime}\right)$ ranged from 0.35 to 0.84 , from 0.46 to 1 , from 0.29 to 0.82 , from 0.14 to 0.49 , and from 0.53 to 1.89 respectively. The microsatellites described here should be useful for the research in population genetics, conservation genetics and evolution of Amur sturgeon.
\end{abstract}

\section{Keywords}

Microsatellite

Cross-species

Acipenser schrenckii

Genetic diversity

\section{Introduction}

Amur sturgeon (Acipenser schrenckii), is a typical riverine species, and it is distributed in the Amur River, which forms the international boundary between China and Russia (J. W. Zhao et al., 2004). Due to its economic importance, the natural populations of this species have declined drastically in the last 30 years as a consequence of overfishing. Environmental pollution, dam construction and habitat damage in the Amur River basin (Shmigirilov, Mednikova, \& Israel, 2007) have also been the other causes of the declination. Therefore, there is a critical need for the conservation and protection of the Amur sturgeon, and several efforts have been taken to support the recovery of the species. It is undeniable that genetic investigation is necessary for sustainable and efficient recovery of the Amur sturgeon. To better address the conservation and management of the species, suitable high resolution molecular markers should be developed. Amur sturgeon and Chinese sturgeon (Acipenser sinensis) belong to Acipenseridae. They have a close relationship in genetic relationship. Chinese sturgeon had been developed a lot of microsatellites to study its genetics. Although a set of microsatellite primers for the Amur sturgeon were developed (Li et al., 2015; Liu, Li, Cheng, Lu, \& Sun, 2014), they are too many alleles in every microsatellite that added difficulties in the genetics study because of the polyploidy derivative nature of the Amur sturgeon genome. And although Amur sturgeon and Chinese sturgeon have a close relationship in genetic relationship, there is no study on the relationship of them. Furthermore, the researchers that have developed the microsatellites of the Amur sturgeon provided no data on the polymorphic information content and the Hardy-Weinberg departure value in this species. In this study, we report a set of novel crossspecies microsatellite markers from Chinese sturgeon developed by next-generation sequencing technology that can be useful for the research in population genetics, conservation genetics and evolution of Amur sturgeon (Vega-Retter \& Véliz, 2015; Xie, Shao, Zhang, \& Peng, 2015; J. Zhao, Zhao, \& Peng, 2014).

\section{Materials and Methods}

Total RNA was isolated from fin tissue of the Chinese sturgeon using Trizol (Invitrogen, USA), 
according to the manufacturer protocol. Then, the cDNA library was created and was sequenced on an Illumina Hiseq2000. The microsatellites were identified that were constrained to perfect repeat motifs of $4 \mathrm{bp}$ from assembled sequences by the Microsatellite Identification tool (MISA: http://pgrc.ipkgatersleben.de/misa/). In total, ninety-six sequences were chosen and were used to design primers using Primer Premier 5.0.

High molecular weight DNA was extracted from 24 Amur sturgeon individuals collected in Yichang City, in Hubei Province, using the rapid salt-extraction method
(Aljanabi \& Martinez, 1997). And the extracted DNA was used as template for polymerase chain reaction (PCR) amplified using the 96-microsatellite that was developed from the Chinese sturgeon as primer in a 25-ul reaction volume consisting of $1 \times P C R$ buffer (TaKaRa), 50-100ng genomic DNA, $0.25 \mu \mathrm{M}$ for each primer, $150 \mu \mathrm{M}$ dNTPs, 1.5mM MgCl 2 and $0.25 \cup$ Taq DNA polymerase (TaKaRa). The following PCR profile was used: $94^{\circ} \mathrm{C}$ for $3 \mathrm{~min}$, followed by 35 cycles of denaturation at $94^{\circ} \mathrm{C}$ for $30 \mathrm{~s}$, annealing at the appropriate temperature (Table 1) for 30 s, extension at $72^{\circ} \mathrm{C}$ for 30 s, and then a final extension

Table 1. Characterization of 22 microsatellite loci in Amur sturgeon

\begin{tabular}{|c|c|c|c|c|c|c|c|c|c|}
\hline Locus & $\begin{array}{l}\text { Repeat } \\
\text { motif(s) }\end{array}$ & Primer sequence(5'-3') & $\mathrm{Na}$ & $H_{E}$ & $H_{O}$ & $\operatorname{Tm}\left({ }^{\circ} \mathrm{C}\right)$ & $P I C$ & $d$ & $\mathrm{H}^{\prime}$ \\
\hline \multirow[t]{2}{*}{ ZHX67 } & $(\mathrm{AGAA})_{11}$ & F:TCTTGCCATCCCTTTGCAGT & 4 & 0.71 & 0.96 & 59 & 0.66 & 0.35 & 1.3 \\
\hline & & R:GAACAGATCCTGTCCGTGGG & & & & & & & \\
\hline \multirow[t]{2}{*}{ ZHX79 } & $(\text { TGTA })_{11}$ & F:TTCTCGCTGGGGTGAAATCC & 4 & 0.7 & 0.92 & 60 & 0.65 & 0.31 & 1.29 \\
\hline & & R:ACAGACAGACAGACACACTCC & & & & & & & \\
\hline \multirow[t]{2}{*}{ ZHX81 } & $(\text { GATA })_{14}$ & F:TGCACCTGTCATCTGCTCAG & 6 & 0.82 & 1 & 60 & 0.79 & 0.22 & 1.73 \\
\hline & & R:AAGGCTTGTTCTGTGGCAGT & & & & & & & \\
\hline \multirow[t]{2}{*}{ ZHX83 } & $(\mathrm{CTAT})_{14}$ & F:TTCACACAGCCAGCTAACCC & 2 & 0.35 & 0.46 & 60 & 0.29 & 0.31 & 0.53 \\
\hline & & R:TTGTGTCCTGAGCTGTAAGAG & & & & & & & \\
\hline \multirow[t]{2}{*}{ ZHX86 } & $(\mathrm{ATAG})_{13}$ & F:AGTAACCTGGCTGTGACAGAC & 6 & 0.83 & 1 & 59 & 0.8 & 0.2 & 1.77 \\
\hline & & R:ATCCCTCAGTCTTGCAGTGC & & & & & & & \\
\hline \multirow[t]{2}{*}{$\mathrm{Z1}$} & $(\text { ATAG })_{15}$ & F:CAGGCAGTCTCCCGCAATAT & 7 & 0.84 & 0.96 & 59 & 0.82 & 0.14 & 1.89 \\
\hline & & R:GCCTGTACACCGTGGCTAAT & & & & & & & \\
\hline \multirow[t]{2}{*}{ Z4 } & $(\mathrm{ACAT})_{10}$ & F:GCAGCTCCTTCCAGTCCTTT & 5 & 0.79 & 1 & 60 & 0.76 & 0.27 & 1.59 \\
\hline & & R:CTGTGGTGGCTTTGAATGACA & & & & & & & \\
\hline \multirow[t]{2}{*}{ Z15 } & $(\text { ATAG })_{14}$ & F:AGCTAGCAACTGAAGCCCTG & 5 & 0.78 & 1 & 60 & 0.74 & 0.28 & 1.55 \\
\hline & & R:ACAGCTGCAGCACACTTTTTG & & & & & & & \\
\hline \multirow[t]{2}{*}{ Z33 } & $(\mathrm{TCTT})_{15}$ & F:ACTCATCAGCCTGAAATCAAGT & 5 & 0.78 & 0.96 & 57 & 0.75 & 0.23 & 1.56 \\
\hline & & R:TGCTTTAGAGGTCTTGCGGG & & & & & & & \\
\hline \multirow[t]{2}{*}{ Z93 } & $(\mathrm{ATCT})_{14}$ & F:GGTGCCGCCTCATAAAACAC & 5 & 0.75 & 0.96 & 59 & 0.71 & 0.28 & 1.48 \\
\hline & & R:TGGGGATTTTGATTGCTCGGT & & & & & & & \\
\hline \multirow[t]{2}{*}{ Z105 } & $(\mathrm{CTTT})_{15}$ & F:CAAGGTAAAGGGGAGTGCCA & 7 & 0.84 & 1 & 59 & 0.82 & 0.19 & 1.89 \\
\hline & & R:CAATCTGCAGGGAGGGGATG & & & & & & & \\
\hline \multirow[t]{2}{*}{ Z114 } & $(\text { TAGA })_{15}$ & F:GCCAACAGCGATAAAAGCAT & 3 & 0.65 & 0.79 & 57 & 0.58 & 0.22 & 1.07 \\
\hline & & R:CCTTCCTGTAAGCCATCTGCA & & & & & & & \\
\hline \multirow[t]{2}{*}{ Z120 } & $(\mathrm{TCTT})_{13}$ & F:CTGTGTCTTCTGCTCCTGGT & 6 & 0.79 & 1 & 59 & 0.76 & 0.27 & 1.64 \\
\hline & & R:GCATGTCAGGGCCGGTATTA & & & & & & & \\
\hline \multirow[t]{2}{*}{ Z121 } & $(\mathrm{ATGT})_{11}$ & F:ACTGAGTGCTCGATTCACACA & 3 & 0.66 & 1 & 59 & 0.59 & 0.52 & 1.09 \\
\hline & & R:GAGACAACGTCGGTCCAGTT & & & & & & & \\
\hline \multirow[t]{2}{*}{ Z125 } & $(\mathrm{AGAT})_{12}$ & F:CTGGCTAAGGTCATGGCCAA & 3 & 0.66 & 1 & 60 & 0.59 & 0.52 & 1.08 \\
\hline & & R:CAAACTTTATTTGGAAAATTGCACAAT & & & & & & & \\
\hline \multirow[t]{2}{*}{ Z130 } & $(\text { TATC })_{10}$ & F:CTGTCAGGCAGCACAAAAGG & 7 & 0.83 & 1 & 59 & 0.81 & 0.2 & 1.86 \\
\hline & & R:TCAGTGTGTGTGATGAAGGCA & & & & & & & \\
\hline \multirow[t]{2}{*}{ Z147 } & $(\text { ATAG })_{15}$ & F:TTCACACTTCACCCCTTGCC & 3 & 0.65 & 0.92 & 60 & 0.58 & 0.42 & 1.07 \\
\hline & & R:CTGGAACCAGCCGGATTCTT & & & & & & & \\
\hline \multirow[t]{2}{*}{ Z152 } & $(\text { TAGA })_{11}$ & F:GCGCCTTTTGGGTTGATGAG & 7 & 0.83 & 0.96 & 60 & 0.81 & 0.16 & 1.84 \\
\hline & & R:CTGCACTTGGGGGTATGACA & & & & & & & \\
\hline \multirow[t]{2}{*}{ Z153 } & $(\mathrm{TCTT})_{13}$ & F:TGGACTGACAACACTGCTCC & 5 & 0.67 & 1 & 60 & 0.62 & 0.49 & 1.28 \\
\hline & & R:ACAGAGCACGTACAGCCAAA & & & & & & & \\
\hline \multirow[t]{2}{*}{ Z162 } & $(\mathrm{AAGA})_{12}$ & F:CGCAATTCCCGATCGTTTGG & 5 & 0.79 & 1 & 60 & 0.76 & 0.27 & 1.58 \\
\hline & & R:ATACACACACTCGAGCACCC & & & & & & & \\
\hline \multirow[t]{2}{*}{ Z166 } & $(\mathrm{ATCT})_{15}$ & F:GTGTTTAGAATGTTTAAACACTGAGGA & 4 & 0.69 & 0.96 & 58 & 0.64 & 0.39 & 1.27 \\
\hline & & R:TGGCCTCAAGTTCAAGCACA & & & & & & & \\
\hline \multirow[t]{2}{*}{ Z167 } & $(\mathrm{GAAA})_{13}$ & F:GCACGAGAGAGACAGGACAA & 6 & 0.75 & 1 & 59 & 0.71 & 0.33 & 1.45 \\
\hline & & R:CAGGTTGAAAGTGCTGGTGC & & & & & & & \\
\hline
\end{tabular}

*The table including Locus, Repeat motif(s), Primer sequence, number of alleles observed $(\mathrm{Na})$, expected heterozygosity $\left(H_{E}\right)$, observed heterozygosity $\left(H_{O}\right)$, annealing temperature $(T m)$, polymorphic information content $(P I C)$, Hardy-Weinberg departure value $(d)$ and Shannon-Wiener Diversity Indices $\left(H^{\prime}\right)$. 
at $72^{\circ} \mathrm{C}$ for $10 \mathrm{~min}$. The products were separated on $10 \%$ polyacrylamide gel stained with silver staining. A pBR332 DNA/Mspl molecular marker (TaKaRa) was used as the standard to determine the size of the alleles.

The statistics of the polymorphic parameters, including the mean expected heterozygosity $\left(H_{E}\right)$, observed heterozygosity $\left(H_{O}\right)$ and Shannon-Weiner Diversity Indices $\left(H^{\prime}\right)$ were calculated using software ATetra1.2 (Puyvelde, Geert, \& Triest, 2010). ShannonWeiner Diversity Indices can estimate Shannon's information index as a measure of gene diversity (Shannon, Weaver, \& Wiener, 1949). The polymorphic information content $(P I C)$ and Hardy-Weinberg departure value $(d)$ were calculated according to formula (Formula 1). $\mathrm{P}_{\mathrm{i}}$ and $\mathrm{P}_{\mathrm{j}}$ is the frequency of $\mathrm{I}$ and $\mathrm{J}$ allele in the group.

$$
\begin{gathered}
P I C=1-\sum_{i=1}^{n} P_{i}^{2}-\sum_{i=1}^{n-1} \sum_{j=i+1}^{n} 2 P_{i}^{2} P_{j}^{2} \\
d=\left(H_{o}-H_{e}\right) / H_{e} \quad \text { (Formula 1) }
\end{gathered}
$$

\section{Results}

In the present study, twenty-two out of ninety-six microsatellites tested for cross-species amplification in Amur sturgeon showed polymorphism (Table 1). Among these ninety-six microsatellites, 5 were monomorphic in all specimens, 16 did not produce any PCR product and
53 produced too low quality results (stutter bands). For example, genotype patterns for locus Z33, locus z147, locus Z167 and locus Z153 in 24 Amur sturgeon individuals are displayed in this paper (Figure 1 and Figure 2). All of them were polymorphic with 2 to 7 alleles per locus and the total number of alleles is 106 . The expected heterozygosity $\left(H_{E}\right)$, observed heterozygosity $\left(H_{O}\right)$, polymorphic information content $(P I C)$, Hardy-Weinberg departure value $(d)$ and ShannonWeiner Diversity Indices $\left(H^{\prime}\right)$ ranged from 0.35 to 0.84 , from 0.46 to 1 , from 0.29 to 0.82 , from 0.14 to 0.49 , and from 0.53 to 1.89 respectively.

\section{Discussion}

Microsatellite marker is an important tool in the genetic research for the conservation and management of fish species (Moghim et al., 2013). In this study, we developed a set of novel cross-species microsatellite markers with next-generation sequencing technology rather than the traditional developments that are laborintensive and time-consuming (Wang, Xiaomu, \& Zhao, 2012). Microsatellite primers developed by Liu et al. (Liu et al., 2014) and Li et al. (Li et al., 2015) contributed greatly to resource of Amur sturgeon. However, they provided no data on the polymorphic information content and the Hardy-Weinberg departure value in the Amur sturgeon. In this study, there is no loci showed significant deviation from the Hardy-Weinberg

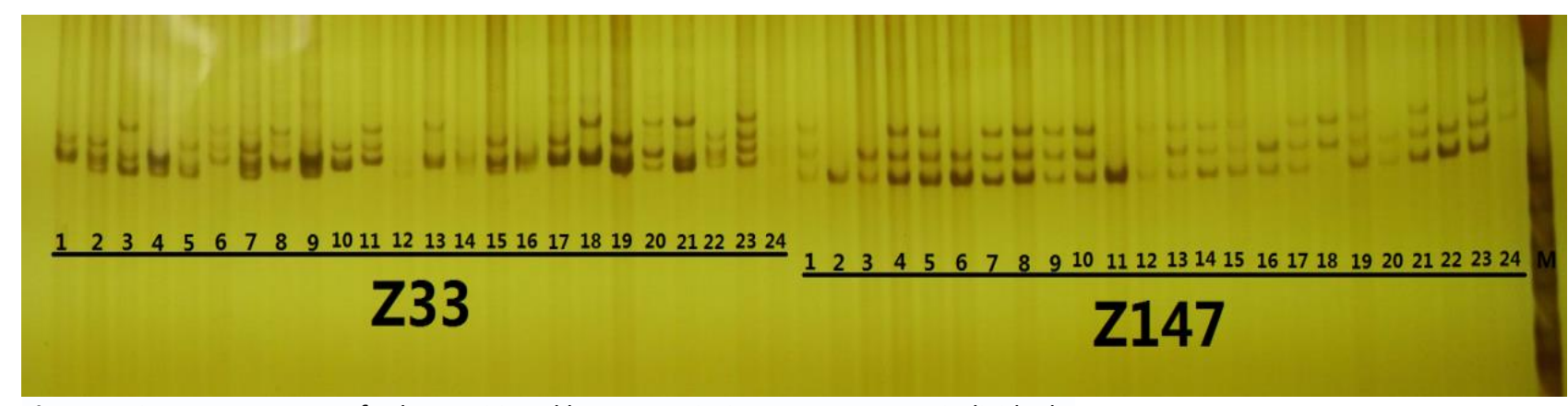

Figure 1. Genotype patterns for locus Z33 and locus z147 in 24 Amur sturgeon individuals.

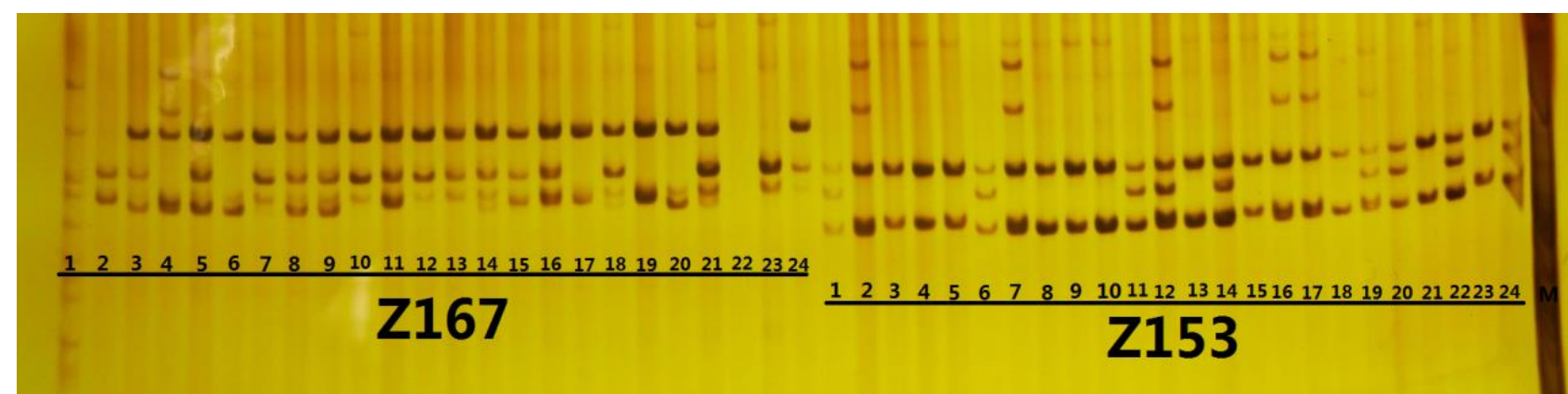

Figure 2. Genotype patterns for locus Z167 and locus Z153 in 24 Amur sturgeon individuals. 
departure value $(\mathrm{P}<0.05)$. twenty-one out of twenty-two microsatellites showed a high PIC (>0.5), which indicated that they were polymorphism. The $H_{E}$ and $H_{O}$ of the microsatellites in this study is higher than the microsatellites developed by Liu et al. (Liu et al., 2014) and Li et al. (Li et al., 2015). The number of alleles per microsatellite developed by Liu et al. (Liu et al., 2014) and Li et al. (Li et al., 2015) ranged from 2 to 18 and 2 to 17 , respectively. In turns, the number of alleles per microsatellite in this study ranged from 2 to 7 . The polyploidy derivative nature of the Amur sturgeon genome has added difficulties in the genetics study of the Amur sturgeon. The microsatellites in this study can help settle the problem of polyploidy nature of Amur sturgeon and provide valuable insight into the relation of the Chinese sturgeon and Amur sturgeon. These novel microsatellite markers will be useful tools to study genetic analyses and protection of Amur sturgeon.

\section{Acknowledgments}

This work was supported by Three Gorges Environment Protection fund, Chinese Three Gorges Corporation (No: XN270). The authors report no conflicts of interest. The authors alone are responsible for the content and writing of the paper.

\section{References}

Aljanabi, S. M., \& Martinez, I. (1997). Universal and rapid salt-extraction of high quality genomic DNA for PCR-based techniques. Nucleic Acids Research, 25(22), 4692-4693.

Li, L. M., Wei, L., Jiang, H. Y., Zhang, Y., Zhang, X. J., Yuan, L. H., \& Chen, J. P. (2015). Rapid development of polymorphic microsatellite markers for the Amur sturgeon (Acipenser schrenckii) using nextgeneration sequencing technology. Genetics and Molecular Research, 14(3), 7910-7913. http://dx.doi.org/10.4238/2015.July.14.16

Liu, Y., Li, C., Cheng, L., Lu, C. Y., \& Sun, X. W. (2014). Development and characterization of new microsatellite markers for Amur sturgeon (Acipenser schrenckii). Conservation Genetics Resources, 12(12), 790-805.

https://dx.doi.org/10.1007/s12686-013-0006-6

Moghim, M., Javanmard, A., Pourkazemi, M., Tan, S. G., Panandam, J. M., Kor, D., \& Laloei, F. (2013). Application of microsatellite markers for genetic conservation and management of Persian sturgeon
(Acipenser persicus, Borodin, 1897) in the Caspian Sea. Journal of Applied Ichthyology, 29(4), 696-703. https://dx.doi.org/10.1111/jai.12195

Puyvelde, K. V., Geert, A. V., \& Triest, L. (2010). Atetra , a new software program to analyse tetraploid microsatellite data: comparison with tetra and tetrasat. Molecular Ecology Resources, 10(2), 331334.

https://dx.doi.org/10.1111/j.17550998.2009.02748.x

Shannon, C. E., Weaver, W., \& Wiener, N. (1949). The mathematical theory of communication. University of Illinois Press, Urbana. 623-656pp.

Shmigirilov, A. P., Mednikova, A. A., \& Israel, J. A. (2007). Comparison of biology of the Sakhalin sturgeon, Amur sturgeon, and kaluga from the Amur River, Sea of Okhotsk, and Sea of Japan biogeographic Province. Environmental Biology of Fishes, 79(3-4), 383-395.

https://dx.doi.org/10.1007/s10641-006-9050-3

Vega-Retter, C., \& Véliz, D. (2015). Isolation and characterization of sixteen microsatellite loci for the rudderfish Kyphosus elegans (Centrarchiformes: Kyphosidae) from Easter Island, discovered with Next Generation Sequencing. Journal of Applied Ichthyology, 31(5), 915-916. https://dx.doi.org/10.1111/jai.12812

Wang, J., Xiaomu, Y. U., \& Zhao, K. (2012). Microsatellite Development for an Endangered Bream Megalobrama pellegrini (Teleostei, Cyprinidae) Using 454 Sequencing. International Journal of Molecular Sciences, 13(3), 3009-3021. https://dx.doi.org/10.3390/ijms13033009

Xie, M., Shao, F., Zhang, Y., \& Peng, Z. (2015). Development and characterization of 21 novel microsatellite markers for the Amur catfish (Silurus asotus Linnaeus, 1758). Journal of Applied Ichthyology, 31(5), 917-918. https://dx.doi.org/10.1111/jai.13391

Zhao, J., Zhao, K., \& Peng, Z. (2014). Development and characterization of eleven microsatellite markers for an endangered cavefish ( Triplophysa rosa Chen and Yang, 2005) using 454 sequencing. Journal of Applied Ichthyology, 30(5), 1056-1058. https://dx.doi.org/10.1111/jai.12474

Zhao, J. W., Qiu, L. Q., Tong-Yan, L. U., Liu, H. B., Yang, Y. H., Xun, D. J., \& Ji-Dan, Y. E. (2004). Effects of feeding rate on growth of Amur sturgeon Acipencer schrenckii. Journal of Fishery Sciences of China. 